\title{
Explanations of Request Formulations by Vietnamese Learners of English in Australia
}

\author{
Xuan V. Ha \\ Ha Tinh University, Vietnam
}

\begin{abstract}
Request performances can be influenced by contextual factors. This paper examines the explanations of the request formulations of six Vietnamese learners of English in Australia. The retrospective interviews provide interesting insights into learners' request wording, such as the underlying motivations and reasoning, that are not apparent in traditional analyses of the forms. First, an analysis of learners' contextual perceptions shows that age differences, perceptions of the relative role relationship, and the formality of the situation influence their request formulation. Second, learners' judgements of politeness and their reported use of politeness devices suggest that learners may rely on supportive moves to manage harmony with their interlocutors. Therefore, the study suggests that appeal to alternative sociopragmatic interpretations could be the main reason for the differences in making requests between Vietnamese learners of English and English native speakers. The findings may advocate the explicit teaching of request speech acts for Vietnamese learners.
\end{abstract}

This study employed retrospective interviews following discourse completion tasks (DCTs) to explore learners' pragmatic knowledge about request speech acts. Requests are both common and sensitive in daily communication. They are particularly important for learners in a studyabroad context who cannot avoid making requests during their stay. Request formulations are influenced by contextual factors which are culture specific (Spencer-Oatey, 2008). To make an appropriate request for a specific communicative situation, a learner has to take into consideration the contextual factors involved, for example, the relative social power and the extent of social distance from the interlocutor, and then be able to select appropriate linguistic forms to carry out the act (Spencer-Oatey, 2008).

Literature on requests has predominantly focused on performance data, such as role-plays or written DCTs. Little research has provided insights into what underlies request performances, especially for Southeast Asian learners of English. Examining transcriptions of verbal reports could be one useful method in interlanguage pragmatics (ILP) research, since this could provide insights into learners' perceptions of speech act situations and the influence of such perceptions on speech act utterances (Cohen, 2004). This study used interviews following written DCTs to examine the reasoning for request formulations by Vietnamese learners of English regarding perceptions about contextual factors, politeness consideration, and the use of supportive moves (i.e., peripheral elements). 


\section{Literature Review}

\section{Interlanguage Requests}

Requests have been one of the most researched speech acts in cross-cultural linguistics and interlanguage pragmatics studies since the 1980s. The majority of studies on requests by nonnative speakers (NNS) of English have been contrastive analyses of native speaker (NS) and NNS comprehension and production (Economidou-Kogetsidis, 2009, 2010). A request consists of a request head act, with or without request modification devices or request modifiers. A request head act is "the nucleus of the request" (Blum-Kulka \& Olshtain, 1984, p. 2002) which helps the requestee to realize the requestive force of the act. It is thus the central part of a request. A request modifier is an additional optional element that may precede or follow the request head act and is important in requesting, in that it helps to vary politeness levels of the requesting act. It does not necessarily change the propositional meanings of the head act but serves to downgrade or upgrade its requestive force (see Schauer, 2009; Trosborg, 1995).

In her framework of rapport management, Spencer-Oatey (2008) proposed four important sets of contextual factors influencing request performances: participant relations, message content, social / interactional roles, and activity type. Participant relations consist of four subfactors: power, distance, interrelationship between power and distance, and the number of participants taking part in the act. Message content is a broader term for what Brown and Levinson (1987, p. 81) and others have termed "imposition" or "rank of imposition." It consists of the considerations of costs, such as time, effort, imposition, inconvenience, and risk. Social / interactional roles refers to relationships such as teacher-student, employer-employee, chairperson-committee member, and friend-friend, as people have the right to have expectations of the other member and the responsibility to carry out obligations. Activity type refers to the conventions about how to structure a particular type of communicative activity.

Mitigating devices in requests function "to reduce any negative impact associated with the speech act" (Spencer-Oatey, 2008, p. 23). Findings from production data research show that NNSs have often been found to differ from their native counterparts in mitigating their requests in particular communication situations (see Al-Ali \& Alawneh, 2010; Economidou-Kogetsidis, 2009). These differences may be culture specific because cultures may differ in both "the frequency of use of given levels of directness in given situations, and also in the rapport management value associated with the level of directness chosen for a given situation" (Spencer-Oatey, 2008, p. 23). For example, in Vietnam, directness is often used in situations where interlocutors have a close relationship or where they wish to enhance solidarity (Sasaki, 1998). However, $\mathrm{Vu}$ (1997) argued that indirectness may be also used in relation to degrees of imposition of utterances.

Aside from ILP and cross-cultural pragmatic studies employing production data, some studies combined the production data by using DCTs with retrospective verbal reports to investigate learners' pragmatic knowledge. Research using retrospective verbal reports as data has provided more insights into what underlies speech act performance, such as learners' thinking, reasoning, or motivations (Cohen \& Olshtain, 1993; Felix-Brasdefer, 2008; Hassall, 2008; Robinson, 1992; Woodfield, 2010).

\section{Requests by Vietnamese Learners of English}

Although there have been several studies dealing with requests by learners of English across a range of languages backgrounds, for example Danish (Trosborg, 1995), Greek (EconomidouKogetsidis, 2009), Jordanian-Arabic (Al-Ali \& Alawneh, 2010), and German (Schauer, 2009), there are only a few exclusively investigating interlanguage requests by Vietnamese learners of 
English. Ha (1998) used a DCT questionnaire to research a group of third-year Vietnamese English majors and compared their requests with those made by a group of Australian English NSs. She found that Vietnamese learners used more direct request strategies (e.g., imperatives) and underused request modifiers in their requests compared to NSs (Ha, 1998). Pham (2001) carried out a study with a group of Vietnamese students in Australia and compared the results with Ha's (1998) to evaluate the effects of students' proficiency levels and length of their residence in the target country on making requests. He found that his participants used more direct requests with fewer internal modifiers (i.e., syntactical modifiers) but more external modifiers (e.g., reasons) than their NS counterparts. His participants were more native-like than Ha's (1998) in employing request strategies and modifications (Pham, 2001). The results suggested that the proficiency levels and length of residence in the target country have positive effects on the acts of requesting of the language learners. This finding is in line with Schauer's (2009) larger study on German learners of English in a study-abroad context, which showed that studying abroad could help learners be more aware of social norms of the target language and thus behave in a more native-like manner.

These studies used performance data, which might provide an incomplete view of learners' pragmatic knowledge. The present study employed retrospective interviews following written DCTs to explore the learners' reflections on their actual requesting utterances. It explores learners' perceptions of contextual factors and the influence of these factors on their request formulations, including the use of strategy types, mitigating device please, and supportive moves.

\section{Research Questions}

This study seeks to answer the following research questions:

1. How do Vietnamese learners of English perceive requesting situations?

2. How do these perceptions influence the request formulations of Vietnamese learners of English?

3. What are learners' perceptions of politeness in requests and how do they achieve politeness?

\section{Participants}

\section{Methodology}

The participants in the study were six Vietnamese students enrolled at a mid-sized multinational university in Victoria, Australia. Four were postgraduates and two were undergraduates. Their ages ranged from 19 to 27 , and all had an IELTS of 6.0 or over and used English as a medium of study and everyday communication. Length of stay in the target language community ranged from 17 to 49 months. To select participants, 120 students in the e-mail list of the Association of Vietnamese students were invited to participate by email. Of 33 who volunteered to participate, three males and three females were then selected randomly.

\section{Data Collection}

Method, instruments, and procedure. The data were collected through DCTs and retrospective interviews. The DCTs employed consist of three scenarios varying along the dimension of relative social power between the requester and the requestee. These scenarios have been used by Ha (1998) and Pham (2001) to examine learners' requesting strategies and modifications. Participants were asked to read the scenarios and write what they would say (see Appendix A). The retrospective interviews in this study were to elicit learners' perceptions of the requesting situations and their evaluations of their request wordings. The interviews 
consisted of both fixed and data-driven questions based on participant responses in the DCTs (see Appendix B).

Participants individually met with the researcher and received instructions for completing the written DCTs, which specified that they should try to understand the scenarios and provide answers as naturally as possible. After the participants finished the scenarios, they were asked to participate in an interview regarding their responses in the DCTs. Both DCT responses and interviews were conducted in English and audio recorded with interviewee consent for transcription and analysis. The same process was administered for every participant. Each interview session lasted from 40 to 50 minutes, yielding about 5 hours of recorded conversation.

\section{Data Analysis}

The DCTs were analysed using Blum-Kulka, House, and Kasper's (1989) coding scheme taken from the Cross-Cultural Speech Act Realization Patterns Project (CCSARP). Participants' requests were categorised into request strategies of the request head acts and types of request modifiers.

Verbal report transcripts were then analysed according to participants' metalinguistic knowledge statements. To examine participants' perceptions of contextual factors and politeness, the metalinguistic statements were coded according to participants' comments relating to participants' perceptions of contextual factors, politeness considerations, perceptions of the politeness marker please, and consideration of supportive moves.

\section{Contextual Factors}

\section{Findings and Discussion}

Most participants reported that they understood the requesting situations and took into consideration various contextual and cultural factors before deciding how to word their requests. They reported noticing the urgency of the requests, the requestive goals, and the relationships between the requester and requestee, such as roles, power, distance, and age. Overall assessment of these factors, sometimes reflecting combinations of factors, contributed to the perceptions of the situations as formal or informal. These perceptions were shown to influence the way participants shaped their requests in the DCTs. The variable of power was found to influence participants' request formulations. However, the nature of the relationship is different from what has been found in the literature.

Power, roles, and rights. Situation 1 (see Appendix A), a police officer asking a driver to show his / her driving licence, was perceived as formal. Four participants commented that in the role of police officer, they should behave politely to keep their image and that a police officer should be responsible for his job and respect others. For example, Participant 1 commented, "[As] I am a police officer, I have to ask nicely [to] the law breaker."

In this situation, the requester has more power than the requestee; the requester also has a legitimate right to ask and the requestee has an obligation to carry out the requested act. BlumKulka and House (1989) claimed that level of directness correlates strongly with the expectation of rights and obligations between the requester and the requestee. This study's findings do not support this claim. This may be due to the influence of the participants' perception that a police officer has an obligation to behave politely as part of their job. This finding shows that "sociality rights and obligations" (Spencer-Oatey, 2008, p. 16) (e.g., rights and obligations between teachers and students, parents and children or police and passengers) 
influence the way learners formulate their requests. However, the influence is not necessarily in the way that their requests' directness correlates with requesters' rights and the requestees' obligations, as suggested in Blum-Kulka and House (1989) and Economidou-Kogetsidis (2010).

Discussing terms related to interlocutors' role, Spencer-Oatey (1996) pointed out that in some cases, interpretations of power in relationship to rights and obligations are not obvious and are complex. Regarding Situation 1, the police officer has a legitimate right to ask for a driver's licence when the driver does not obey the traffic rules; and the driver has an obligation to show it. However, in Vietnamese culture, the driver could have the right to expect the police to behave politely; and the police officer may also have the obligation to behave politely towards the driver.

Participants may be more concerned about their obligation as a police officer to give good service to people. For example, Participant 3 reported, "Yeah, because I'm a police officer, I have to behave politely, that's why I used sir to talk to the driver." They all, thus, would request politely with supportive moves and the query preparatory strategy type. For example, Participant 1 reported how he would make the request: "Excuse me, I'm a police officer on duty. This is my identity card. You have just gone through [a] red light, so could you please show me your driver's license?" The DCT results and reports in this example are consistent with this interpretation. Spencer-Oatey (2008) stated that different cultural groups of people may expect different typical degrees of power and distance and / or socially-defined rights and obligations, which influences their assessments of appropriate language use.

Rapport enhancement. Situation 2 (see Appendix A), asking a new neighbour to help open the front door, was perceived as informal. Participants commented that they would try to make this request in a friendly way. Participant 2 , for example, commented, "I think most about how to make something more friendly, less formal."

Participants' comments show that they held a "rapport enhancement orientation" (SpencerOatey, 2008, p. 32) and attempted to enhance the harmony of their relationship with other interlocutors. They did not try to use request strategies and mitigating devices to avoid threatening the other's face or infringing on the other's sense of sociality rights. Yet, they tried to establish a good relationship with the other (the neighbour). Participant 2 commented, "In Situation 2, I want to be friendly by talking to him before asking him to help." Participants chose to manage the harmony with the other interlocutor (Spencer-Oatey, 2008) or tried to be liked by the other interlocutor by talking in the same way that they talk to friends and relatives. This may be due to the Vietnamese collectivist culture (Hofstede \& Hofstede, 2005) in which speakers tend to establish, maintain, and sustain common grounds and social relationships with the interlocutors (Trần, 2004). Spencer-Oatey (2008) also noted that people of different cultural backgrounds assess contextual factors differently, which has substantial impact on their language use.

Comments from the interviews also show a close relationship between the formality and politeness judgements (Felix-Brasdefer, 2006). Participant 4 commented, "Situation 2 is informal so I use [a] less polite request than in the first situation." In an informal situation, participants would not try to employ indirect requests with internal modification. Three reported that they would use Can you give me a hand? to realize their requests, a relatively direct request used when the requester does not estimate any potential face risk. Participants also reported that they would use informal openers such as hey instead of excuse me in their requests. This finding lends support to Felix-Brasdefer (2006) in that direct requests may not threaten the requestee's face but instead may be used to express closeness or affiliation. 
According to $\mathrm{Vu}(1997$, p. 221), in informal situations, Vietnamese speakers often employ "respectful politeness" strategies, relying on rules of respect and solidarity. In this study, Participant 1, for example, explained that "You show him that you respect him so he will know that you want him to respect you." Participants reported that they would employ more request modifications with formal honorifics (e.g., sir), the past tense of auxiliary verbs (e.g., could), or a consultative device (e.g., would you mind) to formulate their requests (see Situation 1, Appendix A). Participants judged these modifications as important in formulating polite requests. Indirectness is likely to be considered and used in these formal situations (Sasaki, 1998). Consequently, formal situations may be more likely to generate polite requests, while informal situations may be more likely to generate friendly, informal, but not necessarily impolite, requests.

Age and urgency. Situation 3 (see Appendix A), stopping an old man on a country road to borrow a jack to fix a flat tyre, was perceived as urgent and serious, but participants reported that polite requests were necessary. All participants noticed the age difference between the interlocutors, and three considered this situation serious due to its urgency. For instance, Participant 4 commented that "I saw a guy who is older than me and I need his help, the guy, he's older than me. [You] can see the language I use, it's more polite and respect[ful] to the man."

The goal and urgency of the requesting situation and the age difference between interlocutors influenced participants' requests. The DCTs show that the participants would use formal requests and ways of addressing the requestee (e.g., sir) or apologizing (e.g., sorry sir, excuse $m e)$ in this situation. Thus, the requestive goal and request urgency significantly influence how participants shape their requests (Economidou-Kogetsidis, 2010).

Regarding the age difference between interlocutors, all participants considered this a significant factor influencing their request formulation. Age may be one of the most influential factors influencing Vietnamese speakers' language use (Sasaki, 1998). For example, Participant 6 said, "I think most about the fact that he's older than me." The universal social norm is that the young have to communicate with older people respectfully (Hartford \& Bardovi-Harlig, 1992; Le, 2011; Sasaki, 1998). In Vietnamese, there are various kinship terms (Sasaki, 1998) to address others of a different age, such as anh (brother), chị (sister), cô (aunt), chú (uncle), bác (uncle), ông (grandfather), and bà (grandmother). These may influence participants' choice of terms of address and openers of a request. In the DCT, two participants reported that they would address the interlocutor with sir, and two participants would begin with excuse me, both showing formality.

\section{Politeness Considerations}

Participants' comments in the interviews show that they are normally aware of politeness when making a request. All six reported that politeness would need to be considered when making requests. The following example illustrates how participants perceive politeness and why they considered politeness as important:

Politeness is very important because the first thing is [that] you show him that you are very responsible for your job [or] your position and the second thing is [that] you respect him. When you do this, he will know that you ask him to respect you. (Participant 1) 
This participant expresses respectful politeness, which relies on the rule of respect (Sasaki, 1998). However, in some cases, participants reported that they would not want to make a formal request because this would conflict with their attempts to create a friendly atmosphere. This dichotomy is set up clearly in Situation 2, where the power is equal. Participants noted that this situation was informal, thus they reported that they would want to frame their request as they would when talking to friends. For example, when Participant 6 was asked whether she thought about politeness when making requests, she answered, "Yes, but not too much because I want to make it more friendly."

\section{Perceptions of the Politeness Marker Please}

Participants' interview comments show that the use of politeness marker please might be overgeneralised and used with every request. However, sometimes it is interpreted as too formal, and because it might devalue the requester's rights, it is not used. Participants' comments may show that the way please is interpreted could be in some way influenced by participants' first language.

Participant 5 reported that to make a request, she would just use please and a question. This way, her requests could always be shaped in the form of query preparatory strategy, the most common request formulation of both NSs and L2 learners of English (Trosborg, 1995). She reported that she would use please in all three situations. Participant 2 overgeneralised the use of please when he said "please is a magic word" in making requests. He reported that he would use please in Situations 1 and 3. This finding supports previous studies using performance data that suggest L2 learners may overgeneralise the target language pragmatic conventions (e.g., Robinson, 1992). In contrast, Participant 4 reported that he would use please only in the first situation. He considered that the word please should be only used for particular reasons and explained, "You can see that in the first situation (red light), that guy made mistake, not me and I didn't borrow [anything] from him so I didn't say please."

This feeling is more clearly reflected in Participant 6's interview. She reported that she would not use please in any of her three requests because she perceived that please was too formal and might devalue her right to ask in these requesting situations. She would choose not to use please due to her individual identity, not because she lacked knowledge of this politeness marker. In Situation 3, she reported that she would not have the right to ask and the driver has little or no obligation to respond. Yet she still wanted to keep her sense of identity and reported that she would not use please to mitigate her request. She explained, "Because when I put please it seems like that my position in the situation is less strong than I am."

Spencer-Oatey (2008) noted that people have a fundamental desire for others to evaluate them positively. Participants' consideration about their identities may have influenced their language choice, and their first language may have influenced their perceptions. The lexical word please may be equivalent to either xin vui lòng or làm on in Vietnamese. These words are rarely employed but can be used in formal requesting situations or in situations where the rank of imposition is high ((Le, 2011). This is in line with Economidou-Kogetsidis' (2009) study, which found that Greek learners of English underused the politeness marker please due to the influence of Greek.

\section{Supportive Moves}

The study suggests that participants would tend to opt for using supportive moves in every request because they would feel comfortable using them and that supportive moves would be significant in making requests. A blunt request was considered to be inappropriate. Two 
participants reported that they would use supportive moves to show politeness and respect to the interlocutors. Such supportive moves as openers (e.g., excuse me, good afternoon) and honorifics (e.g., sir) were thus used. For example, Participant 4 commented:

As you can see, we are two strangers and we didn't know [each other] before so we just like say [sic] hi or something like that, and the reasons why [I] call[ed] them [the polite form], it's also the politeness in the conversation.

As a part of a collectivist culture (Hofstede \& Hofstede, 2005; Trần, 2004) Vietnamese speakers approach the communicative goal in a circular manner, contrary to individualist cultures. One thus often chooses to talk about background information before getting to the main communicative purpose, as he / she wants to establish rapport and make the interlocutor feel part of speaker's in-group prior to making the main request (also called the head act). In other words, the speaker is oriented towards enhancing rapport and harmony with the interlocutor (Spencer-Oatey, 2008; Vu, 1997). Vu (1997) argued that, in Vietnamese culture, supportive moves may be one of the three most important devices in achieving politeness, the others being kinship terms of address and indirectness. A similar finding was reported in the collectivist Jordanian culture. Al-Ali and Alawneh (2010) suggested that Jordanian learners of English opted to use request grounders (i.e., reasons, explanations, or justifications) because they believed that a grounder is less face-threatening than a request head act. Thus, in this study, making a blunt request before justifying its need could "be considered an act of flippancy or discourtesy especially in situations which involve the social factors of power and distance" (AlAli \& Alawneh, 2010, p. 327). The interview data shows that these Vietnamese participants reported that they would rely more on the use of supportive moves to express their politeness, which can be regarded as respectful politeness $(\mathrm{Vu}, 1997)$. Participants also reported that they would not tend to use language strategically to avoid face threats, but that they would attempt to enhance a good relationship with the other interlocutor.

\section{Conclusion}

This study employed DCTs and retrospective interviews to explore participants' pragmatic knowledge about the speech act of requests. The analyses of participants' comments on their request performance reveal several findings about their perceptions of contextual factors and how these perceptions influence their request formulations, use of the politeness marker please, and supportive moves. The findings show that participants tend to perceive relative power relationships, sociality rights and obligations, and age as the most influential factors.

There are several limitations to this study. First, data from a small number of participants makes it impossible to generalise the findings. Second, this self-report study without any research observation could be easily biased because participants are only reporting what they think they would say, which might not be what they would say in a real situation. Moreover, all of the participants were Vietnamese who share the same first language and cultural background.

However, the study still may suggest that Vietnamese learners of English attempt to enhance rapport and harmony with their requestees in informal situations, which supports SpencerOatey's (2008) theory of rapport management. The study also suggests that Vietnamese learners of English tended to use supportive moves in every request but would not use please frequently because it was perceived as too formal. This may be due to the influence of the Vietnamese language and culture. Therefore, explicit teaching of please in making requests, with specific attention paid to its role in English-speaking culture, may be advisable. Future research should include larger numbers of participants to further examine the use of please by Vietnamese learners of English in making requests. It should also triangulate data 
with role-plays, retrospective verbal reports, and especially, actual observation of speech acts for more generalisable results. The use of participants from various cultural and first language backgrounds should also be employed.

\section{Author Note}

Xuan V. Ha, Ha Tinh University, Vietnam.

This paper is built on the data from the author's Masters thesis, conducted in La Trobe University, Australia.

Correspondence concerning this paper should be addressed to Xuan V. Ha, Ha Tinh University, Vietnam, 447 - 26/3 Street, Dai Nai, Ha Tinh City, Ha Tinh, Vietnam. E-mail: havanxuanht@gmail.com 


\section{References}

Al-Ali, M. N., \& Alawneh, R. (2010). Linguistic mitigating devices in American and Jordanian students' requests. Intercultural Pragmatics, 72 (2), 311-339. http://dx.doi.org/10.1515/IPRG.2010.014

Blum-Kulka, S., \& House, J. (1989). Cross-cultural and situational variation in requesting behaviour. In S. Blum-Kulka, J. House, \& G. Kasper (Eds.), Cross-cultural pragmatics: Requests and apologies (pp. 123-154). Norwood, NJ: Ablex.

Blum-Kulka, S., \& Olshtain, E. (1984). Requests and apologies: A cross-cultural study of speech act realization patterns (CCSARP). Applied Linguistics, 5(3), 196-213. http://dx.doi.org/10.1093/applin/5.3.196

Brown, P., \& Levinson, S. (1987). Politeness: Some univerals in language usage. Cambridge, England: Cambridge University Press.

Cohen, A. D. (2004). Assessing speech acts in a second language. In D. Boxer \& A. D. Cohen (Eds.), Studying speaking to inform second language learning (pp. 302-307). Clevedon: Multilingual Matters.

Cohen, A. D., \& Olshtain, E. (1993). The production of speech acts by EFL learners. TESOL Quarterly, 271), 33-56. http://dx.doi.org/10.2307/3586950

Economidou-Kogetsidis, M. (2009). Interlanguage request modification: The use of lexical/phrasal downgraders and mitigating supportive moves. Multilingua, 28, 79-112. http://dx.doi.org/10.1515/mult.2009.004

Economidou-Kogetsidis, M. (2010). Cross-cultural and situational variation in requesting behaviour: Perceptions of social situations and strategic usage of request patterns. Journal of Pragmatics, 42(8), 2262-2281. http://dx.doi.org/10.1016/j.pragma.2010.02.001

Felix-Brasdefer, C. (2006). Linguistic politeness in Mexico: Refusal strategies among male speakers of Mexican Spanish. Journal of Pragmatics, 38(12), 2158-2187. http://dx.doi.org/10.1016/j.pragma.2006.05.004

Felix-Brasdefer, C. (2008). Perceptions of refusals to invitations: Exploring the minds of foreign language learners. Language Awareness, 173), 195-211. http://dx.doi.org/10.1080/09658410802146818

$\mathrm{Ha}, \mathrm{C} . \mathrm{T}$. (1998). Requests by Australian native speakers of English and Vietnamese speakers of English: A cross communication study in pragmalinguistics. Unpublished master's thesis, La Trobe University, Australia.

Hartford, B. S., \& Bardovi-Harlig, K. (1992). Experimental and observational data in the study of interlanguage pragmatics. Pragmatics and Language Learning, 3, 33-52.

Hassall, T. (2008). Pragmatic performance: What are learners thinking? In E. A. Soler \& A. Martinez-Flor (Eds.), Investigating pragmatics in foreign language learning, teaching and testing (pp. 72-93). Bristol, Buffalo, Toronto: Multilingual Matters.

Hofstede, G., \& Hofstede, G. J. (2005). Cultures and organizations: Software of the mind (2nd ed.). New York, NY: McGraw Hill.

Le, P. T. (2011). Transnational variation in linguistic politeness in Vietnamese: Australia and Vietnam. PhD Thesis, Victoria University. Australia. Available at http://vuir.vu.edu.au/17945/

Pham, X. T. (2001). The effects of proficiency levels and length of residence on requests by Vietnamese speakers of English. Unpublished master's thesis, La Trobe University, Australia.

Robinson, M. A. (1992). Introspective methodology in interlanguage pragmatics research. In G. Kasper (Ed.), Pragmatics of Japanese as native and target language (pp. 27-82). Honolulu, HI: University of Hawai'i Press. 
Sasaki, M. (1998). Investigating EFL students' production of speech acts: A comparison of production questionnaires and role plays. Journal of Pragmatics, 30(4), 457-484. http://dx.doi.org/10.1016/S0378-2166(98)00013-7

Schauer, G. A. (2009). Interlanguage pragmatic development: The study abroad context. London, UK: Continuum.

Spencer-Oatey, H. (1996). Reconsidering power and distance. Journal of Pragmatics, 26(1), 1 24. http://dx.doi.org/10.1016/0378-2166(95)00047-X

Spencer-Oatey, H. (2008). Face, (im)politeness and rapport. In H. Spencer-Oatey (Ed.), Culturally speaking: Culture, communication and politeness theory (2nd ed., pp. 1147). London, UK: Continuum.

Trần, N. T. (2004). Tìm về bản sắc văn hóa Việt Nam [Discovering the identity of Vietnamese culture]. TP Hồ Chí Minh: Nhà xuất bản tổng hợp thành phố Hồ Chí Minh.

Trosborg, A. (1995). Interlanguage pragmatics: requests, complaints and apologies. New York, NY: Mouton de Gruyter. http://dx.doi.org/10.1515/9783110885286

$\mathrm{Vu}, \mathrm{T}$. T. H. (1997). Politeness in modern Vietnamese: A sociolinguistic study of a Hanoi speech community. Doctoral dissertation, University of Toronto, Canada. Available at https://tspace.library.utoronto.ca/bitstream/1807/11003/1/NQ27746.pdf

Woodfield, H. (2010). What lies beneath? Verbal reports in interlanguage requests in English. Multilingua, 29(1), 1-27. http://dx.doi.org/10.1515/mult.2010.001 


\section{Appendix A \\ The Discourse Completion Tasks (Ha, 1998)}

The purpose of this questionnaire is to gather some background information and to find out what you would naturally say in three situations listed below (Part II).

\section{Part 1: Personal Details}

1. Your gender (circle one): Male / Female

2. Your age:

3. Are you doing an undergraduate / postgraduate degree? Your course:

4. When did you arrive in Australia? Month: Year:

\section{Part 2: Three Situations}

Write down what you think you would say in the following situations.

1. You are a police officer on duty. You see a car going through red traffic lights. You stop the car and ask the driver to show you his / her driving licence.

You say:

2. You are a doctor. You have just moved into a new flat. You have difficulty opening the front door. Just at that moment one of your neighbours, who is also a doctor, and whom you talked to yesterday approached you. You want to ask for help.

You say:

3. You are driving along a country road and discover you have a flat tyre. You do not have a jack with you. Another car is coming towards you. You wave down the car. The driver, who is older than you, stops and pops his head out.

You say: 


\section{Appendix B \\ Semi-Structured Interview Schedule}

I would like to ask you about the answers you provided in the questionnaire. All three answers are formulated as requests.

\section{Scenario 1 (repeated for Scenarios 2 and 3)}

1. What did you notice about the situation when you first read the scenario?

2. What did you think most about when you wrote the request?

3. What factors influenced your decision to word your request as you did? Did you consider the relationship between you and the other person in the situation? (If so / if not: what factors did you consider and how did this affect your request?)

4. Did you think about politeness when making the request?

5. Could you give me some other alternative ways that you might have worded a request in this situation?

a. Now looking back over your answer, why do you think you decided to write the phrase [............] when you were making the request? What do you think this phrase does? What does this wording achieve for you when you use it?

b. Why did you use [......] (and not [......] for example) in this situation?

\section{At the End of the Interview}

Were you satisfied with your answers?

Did you think of these requests in Vietnamese and then translate them into English? Do you think this affected your answers?

Do you think the way you learned English affected any of your responses? 